\title{
AC 2010-1776: DOES CONCEPTUAL UNDERSTANDING MATTER: PATTERNS OF ERROR IN SENIOR ENGINEERING STUDENTS PROBLEM-SOLVING IN STATICS?
}

\section{Tameka Clarke Douglas, Purdue University}

Tameka Clarke Douglas is an Assistant Professor in the Faculty of Engineering and Computing at the University of Technology, Jamaica (UTech). Before coming to UTech, Tameka was a PhD student in the School of Engineering Education at Purdue University. She was a George Washington Fellow and Graduate Research Assistant in the Department of Engineering Education, Purdue University. Her primary research interests are studying communities of practice and difficult concepts in science and engineering.

\section{Aidsa Santiago Roman, University of Puerto Rico, Mayagüez}

Aidsa I. Santiago RomA $\tilde{A}_{j} n$ is an Assistant Professor in the Department of Engineering Science and Materials and the Director of the Strategic Engineering Education Development (SEED) Office at the University of Puerto Rico, Mayaguez Campus (UPRM). Dr. Santiago earned a BA (1996) and MS (2000) in Industrial Engineering from UPRM, and Ph.D. (2009) in Engineering Education from Purdue University. Her primary research interest is investigating studentsâ€TM understanding of difficult concepts in engineering science with underrepresented populations. She also teaches introductory engineering courses such as Problem Solving and Computer Programming, Statics, and Mechanics.

\section{Ruth Streveler, Purdue Universtiy}

Ruth A. Streveler is an Assistant Professor in the School of Engineering Education at Purdue University. Before coming to Purdue she spent 12 years at Colorado School of Mines, where she was the founding Director of the Center for Engineering Education. Dr. Streveler earned a BA in Biology from Indiana University-Bloomington, MS in Zoology from the Ohio State University, and Ph.D in Educational Psychology from the University of Hawaii at M?noa. Her primary research interest is investigating students' understanding of difficult concepts in engineering science. 
Does conceptual understanding matter: Patterns of error in senior engineering students problemsolving in Statics?

\begin{abstract}
This paper describes a study that investigates students' explanations of force when describing the errors they made when solving a Statics problem based on the concepts of free body diagram (FBD) and equilibrium. Three male civil and mechanical engineering seniors were asked to think aloud as they solved the fore mentioned problem. Participants' solutions were analyzed using two conceptual frameworks. The first framework describes a substance-based conceptual schema of force that students may have. This framework is based on the works of Reiner, Slotta, Chi and Resnick ${ }^{1}$ and $\mathrm{Chi}^{2}$. The second framework from the works of Steif ${ }^{3}$ describes the common errors that students make in their solutions of Statics problems and the Statics concepts that they represent. Findings of this study show that students who got the answer incorrect made four common errors. In conjunction, when explaining the reasoning behind these errors, students talked about the force(s) as represented in the problem and solution as a substance or a material object.
\end{abstract}

\title{
Introduction
}

The scientific principle taught in Statics is the principle of equilibrium. The primary science prerequisite to understanding the principle of equilibrium is Newtonian mechanics. An understanding of the primary concepts of force and equilibrium according to Newton's laws lays the foundation for understanding the principle of equilibrium. According to Newtonian laws for a system to remain in equilibrium the net forces and torques have to all add up to zero.

Students are expected to draw on their conceptual understanding of Newtonian force as a platform for subsequent learning or sense-making of concepts taught in Statics such as free body diagrams (FBD) and equilibrium ${ }^{4}$. Failure to accurately understand the concept of force may serve to confound their understanding of Statics concepts and in turn their ability to correctly apply these concepts to the solution of statics problems and or more advanced mechanical systems. 
A study was conducted of nine civil and mechanical engineering seniors at a small public school. The students were asked to solve four problems relating to force. Findings from studies of the data suggested that civil and mechanical engineering students do not understand accurately the concept of force. In conjunction, their findings indicate that these students view force as a material object ${ }^{5}$.

These data have been analyzed and reported on before. This paper discusses a follow-up study that takes a more in-depth look at the students' responses to one of the problems. The study was designed as a step in further identifying the misconceptions that students have about force and how these misconceptions are represented in their problem solutions. More specifically, the objective of this study was to investigate students' explanations of force in describing their solution when making errors solving a Statics problem.

\section{Conceptual Frameworks}

Two conceptual frameworks are used in this study. We will use the works of Reiner, Slotta, Chi and Resnick ${ }^{1}$ and $\mathrm{Chi}^{2}$ to examine the hypothesis that students think of force intuitively as a substance or a material object. Secondly, we will use the work of Steif ${ }^{3}$ to analyze the errors in students' solutions to Statics problems and the Statics concepts that they represent.

\section{Substance Based Conception of Force Framework}

A large amount of research has focused on the study of students' misconceptions of abstract physics concepts in the domain of mechanics, such as light, heat, electricity and force ${ }^{6-8}$. In particular, these studies show that students enter into the classroom with preconceived ideas or beliefs of these abstract concepts that are derived from everyday experiences.

Hastenes, Wells and Swackhamer ${ }^{7}$ proposed a taxonomy of misconceptions that students hold about force. As an example, students often believe that only active agents exert force and, in accordance with this notion, that rigid, unmoving objects exert no force. Studies such as Reiner, Slotta, Chi and Resnick ${ }^{1}$ and Slotta, Chi and Joram ${ }^{9}$ indicate that students intuitively reason about these concepts as if they are material objects or are substances. Students assign a substance-based ontology to these concepts when in essence they are process based in character ${ }^{1}$, 
2, 9 . Most students understanding of force is not consistent with the idea that a force is a process of interaction. Instead students intuitively think of force as exhibiting similar behavioral characteristics and properties of material objects. $\mathrm{Chi}^{2}$ describes such a misconception as stemming from students assigning an object-based ontology to a concept that is process based.

A substance-based schema associates the following properties with a concept if it is conceptualized as a material object or substance. The eleven properties are ${ }^{6}$ :

- Pushable - able to push and be pushed

- Frictional - experience "drag" when moving in contact with some surface

- Containable - able to be contained by something

- Consumable - able to be "used up"

- Locational - have a definite location

- Transitional - able to move or be moved

- Stable - do not spontaneously appear or disappear

- Corpuscular in Nature - have surface and volume

- Additive - can be combined to increase mass and volume

- Inertial - require a force to accelerate

- Sensitive to Gravity - fall downward when dropped

It is expected that during Statics instruction, students rely on their knowledge of force as a scaffold for understanding more advanced concepts in Statics ${ }^{3}$. A substance based conception of force is not only faulty and incompatible with Newtonian mechanics but often times resistant to traditional forms of instruction ${ }^{10}$. Therefore, if students rely on a substance based misconception of force as a platform for subsequent learning or sense-making this may impair or confound their understanding of statics concepts. Consequently, this faulty understanding may limit their ability to successfully recall and apply these concepts to the solution of Statics problems. If a student's conception of force plays a central role in his/her understanding of Statics concepts, errors in the underlying structure of knowledge of force may appear as faulty conceptions in Statics which when applied to the solution of problems reveal patterns of errors. 
Common Errors Students Make During Statics Problem Solving Framework

Steif ${ }^{3}$ proposed that the source of errors that students make in solving problems in statics may stem from one or more of the four concepts (shown above) that students failed to understand and apply accurately ${ }^{11}$. Steif ${ }^{3}$ proposed a conceptual framework which highlights a set of four concept clusters considered fundamental to the analysis of engineering systems as represented in statics problems. These conceptual clusters, C1, C2, C3 and C4, respectively are:

1. Forces are always in equal and opposite pairs acting between bodies, which are usually in contact.

2. Distinctions must be drawn between a force, a moment due to a force about a point and a couple. Two combinations of forces and couples are statically equivalent to one another if they have the same net force.

3. The possibilities of forces between bodies that are connected to, or contact, one another can be reduced by virtue of the bodies themselves, the geometry of the connection and/ or assumptions of friction.

4. Equilibrium conditions always pertain to the external forces acting directly on a chosen body, and a body is in equilibrium if the summation of forces on it is zero and the summation of moments on it is zero.

In conjunction, Steif ${ }^{3}$ identified ten common errors that students make in solving Statics problems. Each error was believed to be indicative of lapses in understanding of one or more of the four concepts. These errors (error 1 through to error 10) and their associated conceptual lapses have been identified and are:

1. Failure to be clear as to which body is being considered for equilibrium. (C4)

2. Failure to take advantage of the options of treating a collection of parts as a single body, dismembering a system into individual parts, or dividing a part into two. (C4)

3. Leaving a force off the FBD when it should be acting. $(\mathrm{C} 1, \mathrm{C} 4)$

4. Drawing a force as acting on the body in the FBD, even though that force is exerted by a part which is also included in the FBD. (C1, C4)

5. Failing to account for the mutual (equal and opposite) nature of forces between connected bodies that are separated for analysis. $(\mathrm{C} 4, \mathrm{C} 1)$ 
6. Ignoring a couple that could act between two bodies or falsely presuming its presence. $(\mathrm{C} 2, \mathrm{C} 3)$.

7. Not allowing for the full range of possible forces between connected bodies, or not sufficiently restricting the possible forces. $(\mathrm{C} 2, \mathrm{C} 3)$

8. Presuming a friction force is at the slipping limit, even though equilibrium is maintained with a friction force of lesser magnitude. (C3)

9. Failure to impose balance of forces in all directions and moments about all axes. (C4)

10. Having a couple contribute to a force summation or improperly accounting for a couple in a moment summation. (C2)

These common errors have been identified after years of student observations of problem solving in Statics. These errors are thought to be linked to students' failure to understand one or more Statics concepts ${ }^{3}$.

Litzinger and his colleagues ${ }^{12}$ studied four undergraduate students majoring in engineering who had already taken Statics. These students were asked to draw fully dimensioned free body diagrams (FBD) of the target represented in the problem statement and illustration. The intention of this study was to uncover the sources of errors that students made in their problem solutions. From this study it was found that a major source of errors in problem solving was the recall and use of conceptually erroneous knowledge in determining the solution ${ }^{12}$. An analysis of students' solution of Statics problems reveal patterns of errors that are reflective of consistent misconceptions that students hold.

When a student has inaccurate conceptions, these underlying misconceptions are revealed in the erroneous problem solutions that they generate. From the FBD and calculations, it is not always easy to decipher what the misconception(s) is (are) from the pattern of errors that is seen. In an effort to identify the difficult concepts in Statics, Streveler and colleagues ${ }^{4,5}$ studied how nine civil and mechanical engineering students who were asked to think aloud while they solved four problems involving force. From this study it was found that seniors do not fully understand the concept of force. It is believed that students' misconceptions about force remain prevalent and counterproductive in spite of instruction. Their findings also indicated that engineering seniors may think of force as substances rather than interactions ${ }^{4}$. 
From the review of the research literature, it is believed that a substance-based conception of force can impair or limit a student's ability to accurately understand the concept of force itself or more advanced and related concepts. It is not clear if this misconception of force may also impair or limit a student's ability to understand, recall and apply more advanced and related Statics concepts such as FBD and equilibrium to the solution of Statics problems. The study described in this paper re-looks at the data from Streveler and colleagues ${ }^{4,5}$ earlier study. This follow-up study is a step in trying to investigate whether there exists a link between students' substance-based conception of force and the errors that they make in their solutions of Statics problems.

\section{Research Question}

This paper investigates the link between students' substance based misconceptions of force and the errors that students make in their solutions of Statics problems. The research questions that guide this study are:

1. What are the common errors that students make when solving problems in Statics?

2. What conceptions of force do students apply to the solution of problems in Statics: substance-based, process-based, or both?

3. What is the relationship between students' conception of force and the common errors that they make in solving problem in Statics?

\section{Methods}

The study described in this paper looked at the interviews from three male civil and mechanical engineering seniors. Seniors were used in this study because it was assumed that they had already mastered these fundamental concepts and also should know how to solve these problems. Students were asked to think aloud as they solved a problem based on the target concepts of free body diagram (FBD) and equilibrium ${ }^{13}$.

\section{Materials}

The students were asked to solve a problem taken from an early version of the Statics concept inventory (SCI) ${ }^{14}$. Each question on the SCI was designed to target one or more 
misconceptions that students are believed to have in Statics. The SCI was designed to detect students' conceptual lapses through the patterns of errors that students make in their solutions ${ }^{11}$. The question for this study was given in an open-ended format rather than with the usual multiple choice options (see figure 1).

\section{Question}

Consider the system of blocks connected by cords which wrap around pulleys. The $60 \mathrm{~N}$ block rests on a table. Draw the $\mathrm{FBD}(\mathrm{s})$ required to determine the force of the table on the $60 \mathrm{~N}$ block. What is this force?

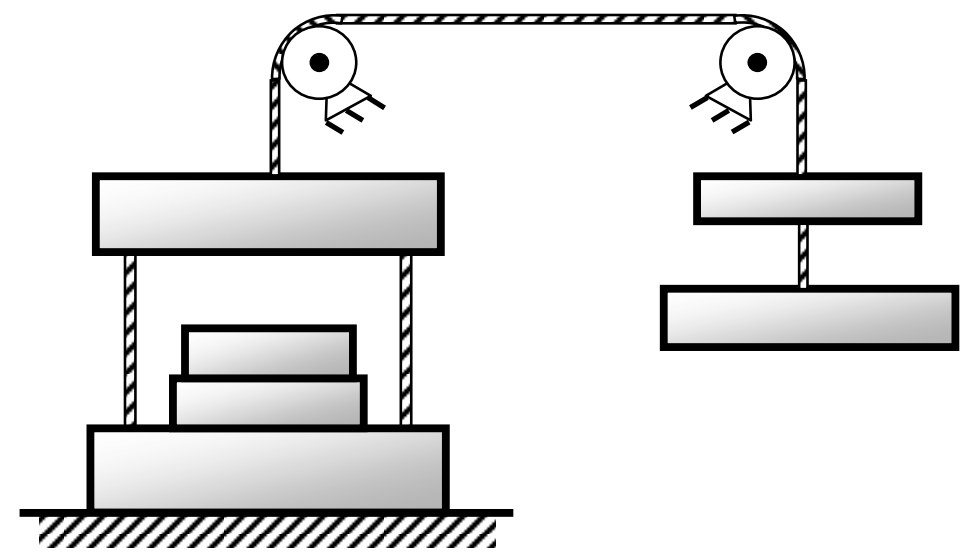

Reference: Earlier version of Statics Concept Test by Paul Steif (Used with permission ${ }^{14}$ )

\section{Tension as represented in the problem}

Tension is a type of force usually applied by a string, rope or cord when it is stretched. For example a rope transfers tension (force) between objects within a system that are connected to it. This transfer of force is not a simple direct causal mechanism where force moves from one end of the rope to the other or through the rope until equilibrium is reached and then the process stops. The transfer of force is actually an emergent process. That is, there is continuous interaction between the rope and other objects of the system connected to it. There is no order or sequence to these interactions between components of the system. The interactions continue even after static equilibrium is reached. Tension is seen as a process of interaction involving objects within a system. 
What is required to solve the problem

Students will have take advantage of separating the system into parts and generating FBDs of these parts. In the FBD students have to accurately account for all the external forces due the supports and the rigid body. At the same time recognizing that the body remains in equilibrium, representing the full range of forces between connected parts and balance of forces in all directions. By accurately representing all forces in parts of the system the student should be able to use force equilibrium equations to solve for the unknown forces in the ropes and subsequently the unknown force of the table.

\section{Coding Scheme}

Student errors in their FBD and calculations were coded and categorized according to one or more of the ten errors that they represented according to the Steif framework. These errors were categorized according to which of the four concepts they failed to represent correctly. The intent of this analysis was to determine if students made similar errors on a given problem.

Students' descriptions of their errors in their problem solution were coded for their explanations of force as they conceived it was represented in the problem or their solution. Students' explanations of force were coded as substance based or process based if they explained or described force as a substance or material object or a process of interaction. If their explanations were unclear their explanations were coded as indeterminate.

\section{Results}

The results from this analysis were used to determine if there were any patterns or link between students' substance based conception of force, the mental models constructed to solve problems (FBD), their calculations, their explanations and the accuracy of the solutions that they generated. Each student's solution and explanations and or descriptions of force will be presented. 
Johnny

Errors in FBD and calculations

Johnny dismembered the system by separating it into parts and he generated FBD for each of these parts. However, Johnny did not represent the forces in the FBD accurately. In some instances, he was not clear which part of the system was being represented in the FBD or did not take in consideration parts of the system in equilibrium that should have been analyzed for unknown forces. He also did not show or account for all forces or balance of forces between connected bodies. Johnny developed force equilibrium equations for parts of the system that he represented in the FBDs. However because his forces represented in the FBD were inaccurate his calculation from the force equilibrium equations gave him the wrong answer. The errors that he made are indicated on the diagram of his solution are presented in Appendix A.

\section{Explanations/Descriptions of Force}

When Johnny described his errors in his FBD and calculations, he explained his solution in terms of force. At these times he described or explained force as a substance or a material object. Johnny did not describe or explain force as though it was a process of interaction. Instead Johnny described the tension in the ropes as through it was located and contained in the cords. He also explained or described force as though it was transitional - able to be moved from the block to the cords and or to the table. Johnny's errors and the explanations of force that used in describing his errors are summarized in Table 1. 
Table 1. Summary of Johnny's errors and his associated explanations of force

\begin{tabular}{|c|c|c|}
\hline Errors & Substance-Based Property of Force & $\begin{array}{l}\text { Explanations of force associated with } \\
\text { errors that student made }\end{array}$ \\
\hline \multirow[t]{3}{*}{$1,2,5,9$} & - Containable/Locational & - It's the tension in the cable \\
\hline & - Containable/Locational & $\begin{array}{l}\text { - There's tension in the cable between the } \\
30 \mathrm{~N} \text { and } 40 \mathrm{~N}\end{array}$ \\
\hline & - Locational & - You got $70 \mathrm{~N}$ on the cable here \\
\hline \multirow[t]{3}{*}{5,9} & - Containable/Locational/Transitional & $\begin{array}{l}\text { - Trying to combine all the weights and all } \\
\text { the tensions to get an idea of how much } \\
\text { force is being taken off the left hand side } \\
\text { of the system }\end{array}$ \\
\hline & - Containable/Locational & $\begin{array}{l}\text { - That's what I calculated for the tension in } \\
\text { the two cables that } 60 \mathrm{~N} \text { block }\end{array}$ \\
\hline & - Containable/Locational & $\begin{array}{l}\text { - From there went on to the } 60 \mathrm{~N} \text { block, } 25 \mathrm{~N} \\
\text { block and the } 15 \mathrm{~N} \text { block, the tension in the } \\
\text { cables,... }\end{array}$ \\
\hline \multirow[t]{2}{*}{$1,2,3,4$} & - Containable/Locational & $\begin{array}{l}\text { - The tension }(40 \mathrm{~N}) \text { in the cables that hold } \\
\text { the } 60 \mathrm{~N} \text { block up, plus the } 25 \mathrm{~N} \text { and the } 15 \\
\mathrm{~N} \text { block }\end{array}$ \\
\hline & - Containable/Locational/Transitional & - Force from the table on the $60 \mathrm{~N}$ block \\
\hline
\end{tabular}

Harry

\section{Errors in FBD and calculations}

In his solution, Harry attempted to dismember the system into parts in order to analyze for the unknown forces. However, Harry made the repeated mistake of failing to be clear as to which part of the system was being analyzed for equilibrium. He also overlooked possibilities of dismembering the system at critical points or failing to treat a collection of parts as a single body. For the FBDs that he did generate, some of the forces were represented inaccurately. There was no force equilibrium equations presented in his solution nor did he talk about them in his 
explanations. He talked about adding forces together but no mention of all forces having to add to zero for a system or part of a system in equilibrium. His solution is presented in Appendix A.

\section{Explanations/Descriptions of Force}

Harry talked about force in a similar manner to Johnny when describing his thought process when making errors. He talked about the "tension into" the ropes and "tension between" the blocks and the rope. This indicates that he thinks the tension is locational (located in the ropes). He also describes force as transitional - as pulling the system - instead or thinking of the rope as pulling on the blocks with a given force. A summary of his errors and explanations of force are shown in Table 2 below.

Table 2. Summary of Harry's errors and his associated explanations of force

\begin{tabular}{|c|c|c|}
\hline Error & Substance-Based Property of Force & $\begin{array}{l}\text { Explanations of force associated with } \\
\text { errors that students made }\end{array}$ \\
\hline $1,2,4$ & - Undetermined & $\begin{array}{l}\text { - It would need to exert a force by } 70 \text {. To } \\
\text { counteract that one }\end{array}$ \\
\hline \multirow[t]{5}{*}{$1,2,5,9$} & - Containable/Locational & $\begin{array}{l}\text { - So first of all I need to find the tension } \\
\text { into between this one and this one }\end{array}$ \\
\hline & - Containable/Locational/Transitonal & $\begin{array}{l}\text { - So the total is } 90 \mathrm{~N} \text { and its going to } \\
\text { tension half and half into here }\end{array}$ \\
\hline & - Gravity Sensitive & $\begin{array}{l}\text { - This whole mass is dropping down due } \\
\text { to gravity }\end{array}$ \\
\hline & - Pushable & - $70 \mathrm{~N}$ pull that way \\
\hline & - Pushable & $\begin{array}{l}\text { - And it's (70N) trying to pull this whole } \\
\text { system up }\end{array}$ \\
\hline
\end{tabular}

Jerome

Errors in FBD and calculations

Jerome drew two FBD of parts of the system. Jerome made several errors in his FBD. He failed to take advantage of further dividing the system into parts to analyze for the unknown tensions. In the FBD Jerome represented the forces inaccurately by failing to impose balance of forces, account for all unknown forces and adding forces where they are not exerted. 
Jerome's explanations of force were used to describe his problem solving process when making the errors. Jerome on several occasions spoke about tension as though it was located in/on the ropes or as though there was force moving from the table to the blocks. Jerome as well as Johnny believe that it is the force in the rope that prevents the rope from "tearing apart." His solution is shown in Appendix A and Table 3 summarizes his explanations and the errors with which they were associated with.

Table 3. Summary of Jerome's errors and his associated explanations of force

\begin{tabular}{|c|c|c|}
\hline Error & Substance-based Property of Force & $\begin{array}{l}\text { Explanations of force associated with } \\
\text { errors that students made }\end{array}$ \\
\hline \multirow[t]{2}{*}{$1,2,5,9$} & - Containable/Locational & - There is obviously tension in this rope \\
\hline & - Containable/Locational/Transitional & $\begin{array}{l}\text { - Assume that the tension from the } 50 \mathrm{~N} \text { to } \\
\text { the } 30 \mathrm{~N} \text { is the same all around }\end{array}$ \\
\hline $1,2,3,9$ & - Containable/Locational & $\begin{array}{l}\text { - There's a force on each of the cords here } \\
\text { that makes it so that they don't tear apart. }\end{array}$ \\
\hline $1,2,3,9$ & - Containable/Locational & $\begin{array}{l}\text { - The tension on this one I'm going to call } \\
\text { T1.. the tension on the two cords between } \\
\text { the } 50 \mathrm{~N} \text { and the } 60 \mathrm{~N} \text { blocks, they've got } \\
\text { to be the same }\end{array}$ \\
\hline $1,2,3,9$ & - Containable/Locational & - The tension on that cord's got to be $40 \mathrm{~N}$ \\
\hline $1,2,3,9$ & - Containable/Locational & - There's tension on each one of the cords \\
\hline $1,2,3,9$ & - Containable/Locational/Transitional & $\begin{array}{l}\text { - There'd have to be one up from the table, } \\
\text { equal and opposite }\end{array}$ \\
\hline $1,2,3,9$ & - Containable/Locational & $\begin{array}{l}\text { - The tension in the two or the tension in } \\
\text { cord between the } 50 \mathrm{~N} \text { and the } 50 \mathrm{~N}\end{array}$ \\
\hline $1,2,3,9$ & - Containable/Locational & $\begin{array}{l}\text { - I guess equal and opposite forces because } \\
\text { it is not tearing apart }\end{array}$ \\
\hline
\end{tabular}

\section{Discussion}

1. What are the common errors what students make when solving problems in Statics?

An analysis of the student interviews indicated that students showed patterns of errors in their solutions that represented misconceptions about the target concept. Evidence of these common errors were identified in students' FBD, calculations and explanations of their problem solving processes. The following list of errors ${ }^{11}$ were found and is repeated here for convenience. They are:

11. Failure to show clearly in their illustration which body is being considered for equilibrium 
12. Failure to treat a collection of parts as a single body, dismembering a system into its parts or dividing a part into two as needed

13. Representing a force in the FBD as acting on the body, when that force is exerted by a part which is included in the body

14. Representing a force in the FBD acting on the body of the FBD, when that force does not directly act on the body

15. Failure to account for the mutual nature of forces between bodies that are connected that are separated for analysis

16. Failure to impose balance of forces in all directions and moments about all axes.

No two students presented the same solutions. However they made similar errors. Table 5 below shows the common errors that each student made in their solution to the problem on FBD and equilibrium. Only one student made all five errors associated with the concept.

However among all the students errors 1,2,5 and 9 were made. All four errors are associated with a misunderstanding of the concept of equilibrium according to Steif's framework ${ }^{3}$. This indicates that students are repeatedly failing to know how and where to separate the system into parts in order to analyze the unknown forces. In addition, this indicates they are not accounting for all and or the balance of the forces among connected parts as should be represented in the FBD.

A common trend in the students' solutions was grouping of the errors. Errors 1 and 2 and errors 5 and 9 were made together on a given FBD representation. This grouping of errors may suggest that the errors are conceptually closely related and that both errors are indicative of the same or closely related conceptual lapse.

2. What conceptions of force do students apply to the solution of problems in Statics: substance-based, process-based, or both?

Phrases describing and or explaining force such as "force is being taken off," "force on the rope," "tension in the rope" were coded as indicating that the student talks about force as though it is an object or substance. These data of students' explanations of their problem solving processes indicate that students have a substance-based conception of force. Analysis of students 
interview protocols indicate that all of these students sometimes talk about force as a direct casual process.

All students describe or explain force as having a location or contained. They describe force as located or contained on or in the rope. All students describe the force as transitional, that is, being able to move from the rope to the blocks or from the left side of the system to the right side of the system or from the table to the blocks. This suggests that they think of the force as moving through the system in a sequential manner; in other words from one end of the rope to the other. Similar results were found in another study done by Santiago Roman and colleagues ${ }^{15}$.

The total number of statements that were coded as substance-based for each student is summarized in the table below.

\section{Table 5. Common Errors and number of substance-based explanations/descriptions of force for each student}

\begin{tabular}{|c|c|c|}
\hline Student & Errors & No. of substance based explanations \\
\hline Johnny & $1,2,3,4,5,9$ & 11 \\
\hline Harry & $1,2,4,5,9$ & 7 \\
\hline Jerome & $1,2,3,5,9$ & 11 \\
\hline
\end{tabular}

3. What is the relationship between students' conception of force and the common errors that they make in solving problem in Statics?

Students used verbiage that indicated a substance-based conception of force more than once in explaining their problem solving process when making errors. Students repeatedly used the same verbiage to describe force such as "on" "in" "from" "taken off." This repeated use suggests that they believe or understand these descriptors to represent the behavior or property of force as represented in the problem and their solution. Describing force more than several times as contained, located or transitional when describing their error indicates the primary role this misconception of force plays when reasoning about the concepts of FBD and equilibrium in the problem.

Students showed errors in their FBD and their explanations of their solution that reflect misconceptions about the concepts of FBD and equilibrium. These students showed evidence of having a robust misconception of force because of repeatedly using verbiage to describe force as 
a material object. Results from these data suggest that when thinking about the problem and or reasoning about the solution to the problem, students rely on their understanding of force as a material object.

\section{Conclusion and Significance}

The results showed that the errors made by students were typical among students who produced an inaccurate solution to the problem. The common errors that students made suggest that they had misconceptions about the Statics conceptions of FBD and equilibrium. This work supports Steif's proposition ${ }^{11}$ that the common errors that students make when solving Statics problems reflect the misconceptions of concepts taught in Statics.

The results of this study are a step towards identifying the sources of students' misconceptions that are most prevalent and counter-productive to successful problem solving in Statics. Findings from this study suggest that students' conception of force whether faulty or otherwise play a primary role in their reasoning about concepts such as FBD and equilibrium as represented in Statics problems. In addition, our findings suggest a link between students' ability to successfully solve problems in Statics and their misconception of force as a material object.

This study begins to link errors in Statics problem solving with errors in conceptual understanding in an effort to uncover the primary source of misconceptions. This study is the first to attempt to directly link substance-based misconceptions of force and the common errors that students make when solving problems in Statics. This is a step in trying to link together or understand if there is a conceptual error that relates to or underlies these two frameworks.

One limitation of the study is that all the students with codable solutions incorrectly solved the target problem. Thus, a comparison between those students who correctly and incorrectly solved the problem cannot be made with this data. The next step for this study will be to look at data from a larger number of students (including those with correct and incorrect answers) and their responses to more than one problem. 


\section{References}

1. Reiner, M., et al., Naive Physics Reasoning: A Commitment to Substance-Based Conceptions. Cognition and Instruction 2000. 18(1): p. 1-34.

2. Chi, M.T.H., Commonsense Conceptions of Emergent Processes: Why Some Misconceptions Are Robust. Journal of the Learning Sciences, 2005. 14(2): p. 161-199.

3. Steif, P.S. An articulation of the concepts and skills which underlie engineering statics. in Proceedings of the 34rd ASEE/IEEE Frontiers in Education Conference. 2004. Savannah, GA.

4. Streveler, R.A., et al. The Development of a Professional Knowledge Base: The Persistence of Substance-based Schemas in Engineering Students. in American Educational Research Association. 2006.

5. Streveler, R., et al., Identifying and investigating difficult concepts in engineering mechanics and electric circuits, in American Society of Engineering Education 2006: Chicago, IL.

6. Reiner, M., et al., Naive physics reasoning: A commitment to substance-based conceptions. Cognition and Instruction, 2000. 18(1): p. 1-34.

7. Hestenes, D., M. Wells, and G. Swackhamer, Force Concept Inventory. The Physics Teacher, 1992. 30(3): p. 141-158.

8. Ioannides, C. and S. Vosniadou, The changing meanings of force. Cognitive Science, 2002. 2(1): p. 5-62.

9. Slotta, J.D., M.T.H. Chi, and E. Joram, Assessing Students' Misclassifications of Physics Concepts: An Ontological Basis for Conceptual Change. Cognition and Instruction, 1995. 13(3): p. 373-400.

10. Chi, M.T.H., Commonsense Conceptions of Emergent Processes: Why Some Misconceptions Are Robust. 2005, Lawrence Earlbaum. p. 161-199.

11. Steif, P.S. and J.A. Dantzler, A Statics Concept Inventory: Development and Psychometric Analysis. Journal of Engineering Education, 2005. 94(4): p. 363-371.

12. Litzinger, T., et al., A cognitive study of modelling during problem-solving, in Proceedings of the ASEE Annual Conference \& Exposition. 2006: Chicago, IL.

13. Streveler, R., et al., Identifying and investigating difficult concepts in engineering mechanics and electric circuits, in 2006 ASEE Annual Conference \& Exposition: Excellence in Education. 2006: Chicago, IL.

14. Steif, P., Personal Communication with Steif about questions on the SCI, T. Clarke Douglas, Editor. 2009: Lafayette.

15. Santiago Román, A.I., Clarke Douglas, T., Enersen, D. L., Streveler, R. A., Geist, M. R. , Sulzbach, C. S. , Senior Engineering Students' Conceptualization of Force: The Relationship Between Two Different Conceptual Frameworks, in AERA Annual Meeting. 2009: San Diego, CA.

\section{Acknowledgment}

Material used in this study was supported by the National Science Foundation under Grant No. ESI-0227558, which funds the Center for the Advancement of Engineering Education (CAEE). CAEE is a collaboration of: Colorado School of Mines, Howard University, Stanford University, University of Minnesota, and University of Washington.

Monica R. Geist at the University of Northern Colorado and Candace S. Sulzbach at Colorado School of Mines are acknowledged for their prior work in this study. 


\section{Appendix A}

Johnny's Solution

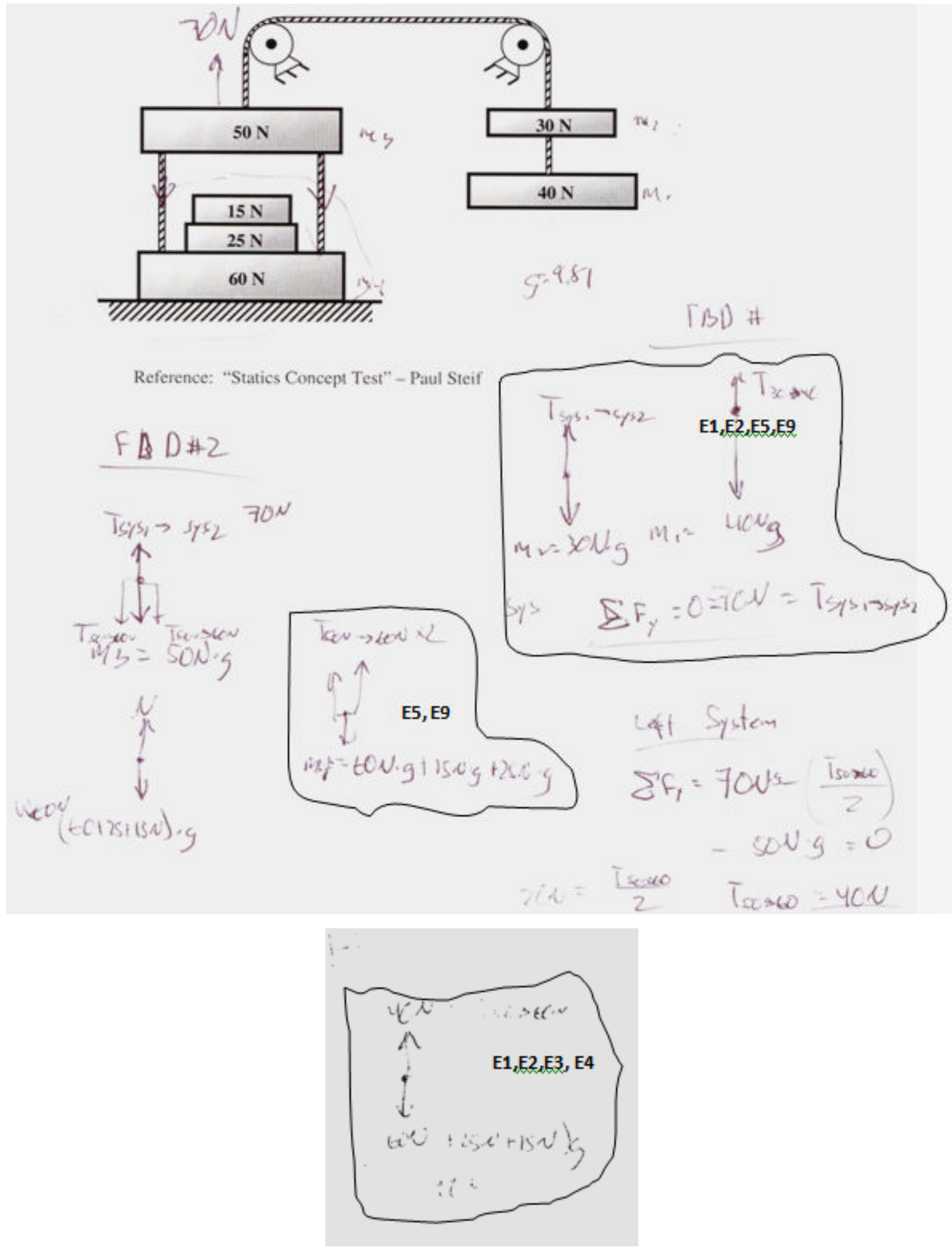


Harry's solution

What is this force?

Asceme paby is protioless

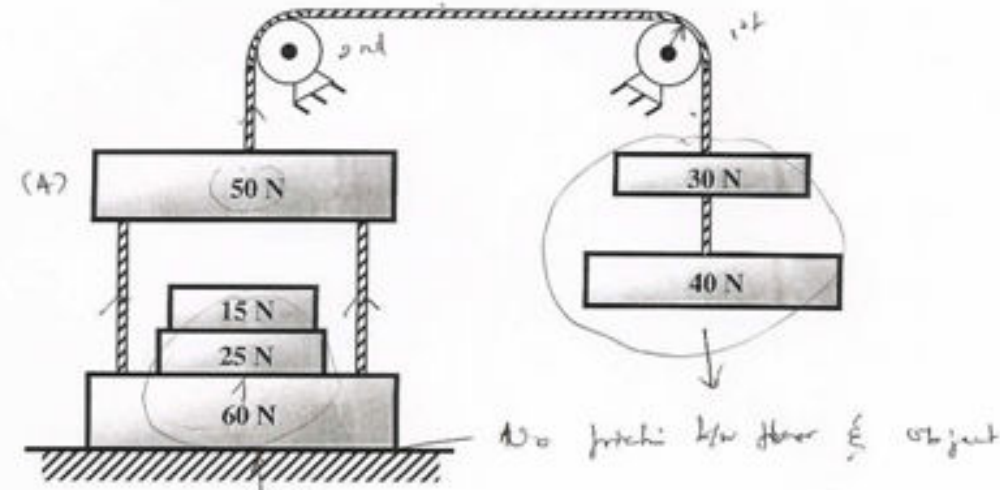

$N$ ?

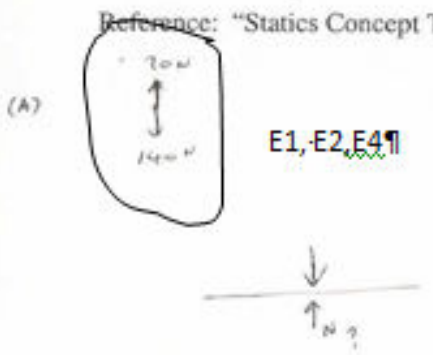

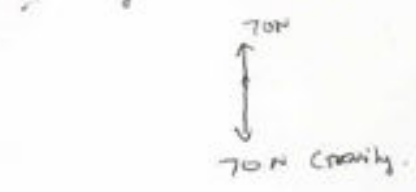

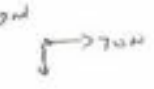

7ore- $]_{7 \rightarrow \pi}^{14 t}$
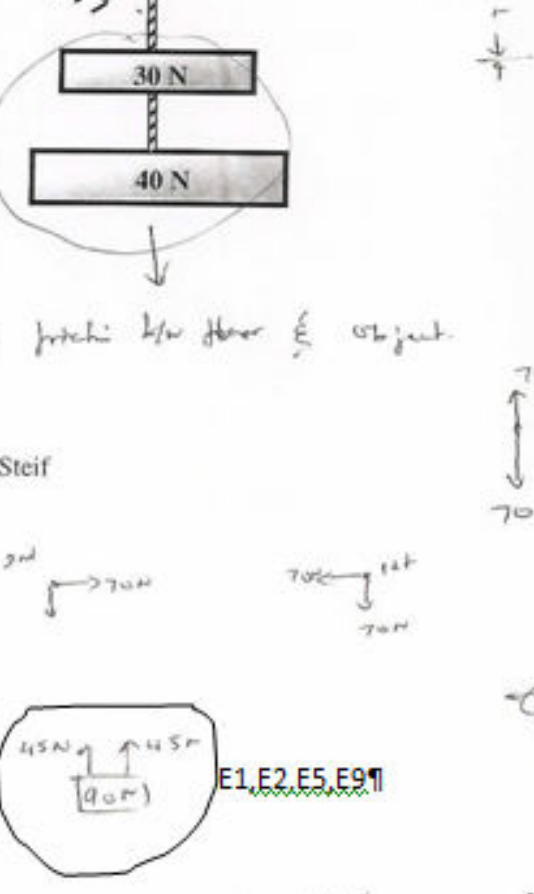

+F?

$90 N+50 N=1400$

2

Pow Forle = Tow

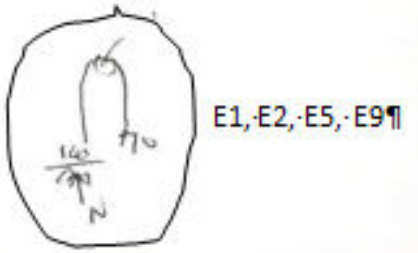

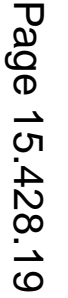


Jerome's solution

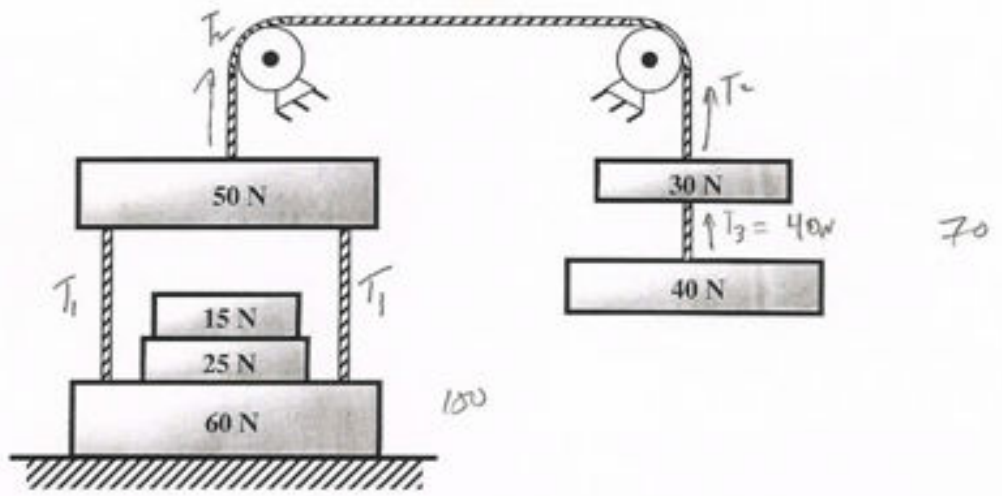

Reference: "Statics Concept Test" - Paul Steif

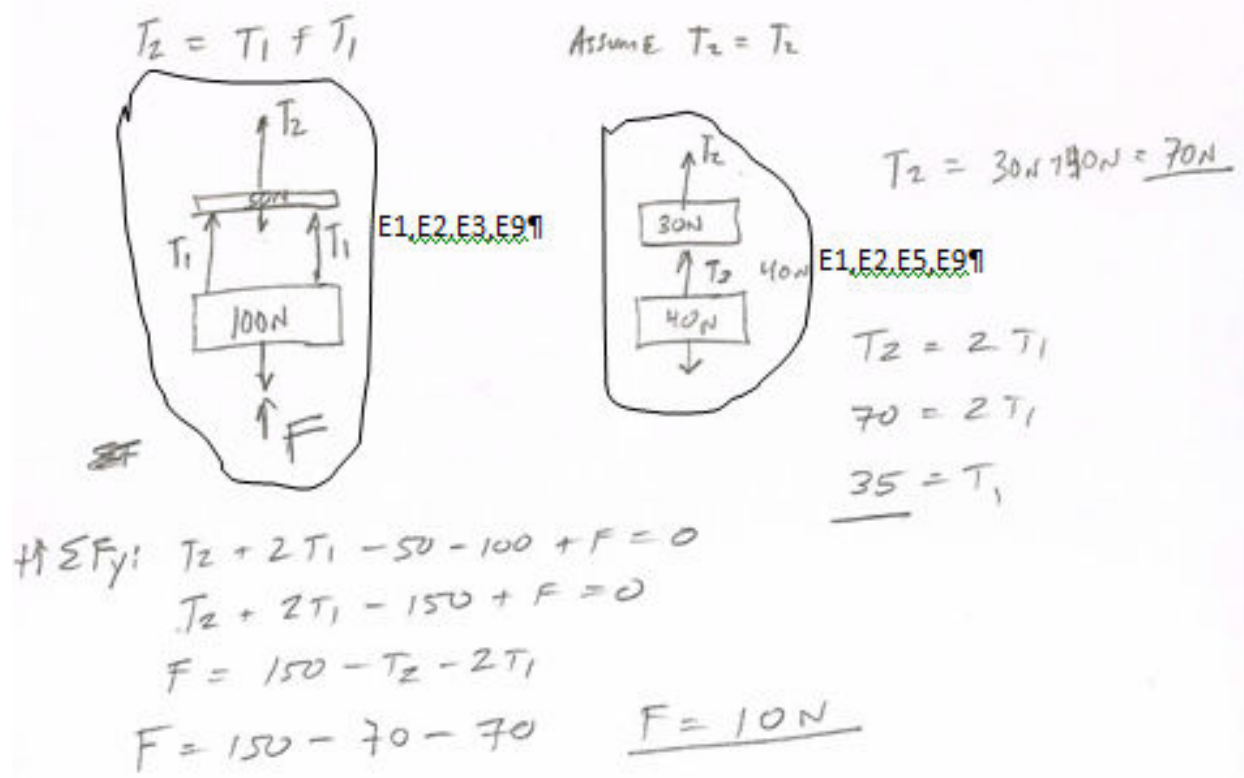

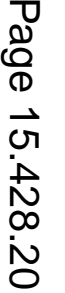

